\title{
Quantification of Oxygen Nanobubbles in Particulate Matters and Potential Applications in Remediation of Anaerobic Environment
}

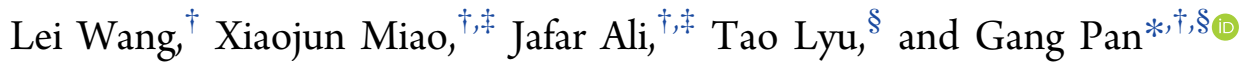

${ }^{\dagger}$ Department of Environmental Nanotechnology, Research Center for Eco-environmental Sciences, Chinese Academy of Sciences, 18 Shuangqing Road, Beijing 100085, P. R. China

${ }^{*}$ Research Center for Environmental Material and Pollution Control Technology, University of Chinese Academy of Sciences, Beijing 100049, P. R. China

${ }^{\S}$ School of Animal, Rural and Environmental Sciences, Nottingham Trent University, Brackenhurst Campus, Southwell NG25 0QF, U.K.

\section{Supporting Information}

ABSTRACT: Interfacial nanobubbles can exist on various hydrophobic and hydrophilic material interfaces. There are diverse applications for oxygen nanobubbles, which are closely related to their content and long-term stability. However, it remains challenging to determine the amount of nanobubbles loaded in a porous material. In this study, a novel method was used to quantify the total amount of oxygen nanobubbles loaded onto irregular particulate materials. Different materials were evaluated and their oxygen-loading capacities were found to be as follows: activated carbon $(\mathrm{AC})>$ zeolite $>$ biochar $>$ diatomite $>$ coal ash $>$ clay. Significant differences in oxygenloading capacities were mainly ascribed to differences in the specific surface area and hydrophobic/hydrophilic properties of the materials. The total oxygen loading on AC achieved using the high pressure loading method was higher than that achieved by the temperature variation method. This new quantitative method provides the possibility for the manipulation of oxygen nanobubble materials in practical applications and it is anticipated to be an important supplement to the existing methods of characterizing interfacial oxygen nanobubbles. Our results demonstrate that materials containing oxygen nanobubbles can significantly increase the dissolved oxygen and oxidation reduction potential in anaerobic systems. With the addition of oxygen-loaded materials (such as AC), the survival time of zebrafish was prolonged up to $20 \mathrm{~h}$ in a deoxygenated water system, and the germination rate of Vallisneria spiralis was also increased from 27 to $73 \%$ in an anaerobic sediment.

\section{INTRODUCTION}

Nanobubbles are gas-filled bubbles that spontaneously form at the interface of solid surfaces and aqueous solutions. ${ }^{1}$ The first experimental evidence of the existence of nanobubbles on various hydrophobic surfaces was provided in 2000 using tapping-mode atomic force spectroscopy (AFM) ${ }^{2,3}$ During the last decade, nanobubbles have already been widely used in the fields of medicine, ${ }^{4}$ physiology, ${ }^{5}$ and water treatment. ${ }^{6}$

Various methods have been established for the preparation of nanobubbles, such as solvent-exchange, ${ }^{7,8}$ temperature gradient, ${ }^{9}$ microwave, ${ }^{10}$ pressure reduction, and electrochemical methods. ${ }^{11-14}$ Three types of nanoscale gas domains, known as surface nanobubbles, ${ }^{15-17}$ nanopancakes, ${ }^{18-20}$ and bulk nanobubbles, ${ }^{21,22}$ have been characterized by various techniques, such as AFM, spectroscopic methods, rapid cryofixation/freeze fracture, quartz crystal microbalance, neutron reflectometry, and X-ray reflectivity. These techniques can efficiently provide bubble images and relevant information, but they are still limited to relatively flat substrates, such as highly oriented pyrolytic graphite, ${ }^{23-25}$ mica, ${ }^{26}$ gold, ${ }^{27}$ polystyrene, ${ }^{28,29}$ and silicon surfaces hydrophobized by silanization. ${ }^{30}$ Nanobubbles can also form and exist on porous materials with irregular surface structures, but the previously mentioned techniques are not suitable for nanobubble analysis. In our previous study, we demonstrated that synchrotronbased scanning transmission soft X-ray microscopy can be used to detect oxygen nanobubbles formed on the diatomite particle-water interface under ambient conditions. ${ }^{31}$ However, this method is heavily dependent on the advanced synchrotron facility. More importantly, it is challenging to obtain the absolute loading or the total amount of nanobubbles formed on the porous solid material surfaces in the suspension because of the unknown density and inner pressure of the nanoscale gas state. ${ }^{32,33}$ Thus, to comprehensively evaluate the nanobubbles

Received: April 22, 2018

Accepted: August 22, 2018

Published: September 5, 2018 
at irregular surface interfaces, a quick and easy method of quantifying nanobubbles is urgently needed.

Oxygen-filled nanobubbles (oxygen nanobubbles) have potential applications in various research fields including nanofluidics, ${ }^{34}$ nanochemistry, ${ }^{35,36}$ nanomechanics, ${ }^{37}$ nanomedicine, ${ }^{38,39}$ and environmental treatment because of their ability to produce free radicals. Oxygen nanobubbles have also been employed for detoxification of water and degradation of organic compounds in wastewater treatment. ${ }^{40-42}$ Moreover, oxygen nanobubbles loaded on porous solid particles of natural clay can be purposely delivered to eutrophic shallow lakes or anoxic sediment and efficiently revive polluted lakes. ${ }^{4-48}$ Determining the highest possible loading of surface oxygen nanobubbles in modified macroscopic particles is essential for the application of nanobubbles in remediation of an anoxic sediment and eutrophication in aquatic environments.

The aim of this study is to develop a quick and easy absorption method to measure the total amount of oxygen nanobubbles loaded in a solid suspension. Various particles, including activated carbon (AC), biochar, diatomite, zeolite, coal ash, and clay, were selected as the oxygen nanobubble carrier using the temperature gradient and high-pressure loading methods. The oxygen nanobubble loading capacities and rates were quantified and compared by the proposed method. Moreover, the potential anaerobic sediment-remediating abilities of the aforementioned materials were also evaluated in lab-scale column experiments. The present study will provide a great choice of loading materials and manipulation methods for the use of oxygen nanobubbles in the field of environmental remediation.

\section{RESULTS AND DISCUSSION}

2.1. Oxygen Nanobubble Loading in the $A C$ Suspension. In this study, nanobubbles were prepared by a simple and efficient procedure, that is, the temperature variation method. ${ }^{49,50}$ When the temperature in the oxygen solution $(25 \mathrm{mg} / \mathrm{L})$ was increased from 5 to $60{ }^{\circ} \mathrm{C}$, the generated oxygen nanobubbles were analyzed using NanoSight nanoparticle tracking analysis (NTA) technology. As presented in Figure 1, nanobubbles were formed with a mean diameter of $182 \mathrm{~nm}$, and the total number density of nanobubbles in the water system was $3.10 \times 10^{8}$ particles $/ \mathrm{mL}$. Meanwhile, nanobubbles were also formed in the suspension system with AC $(5 \mathrm{~g} / \mathrm{L})$ under the same initial oxygen concentration $(25$ $\mathrm{mg} / \mathrm{L}$ ) and temperature gradient. From the results in Figure 2, the total number density of bulk nanobubbles in the liquid was decreased dramatically to $1.85 \times 10^{8}$ particles $/ \mathrm{mL}$, and this reduction may be due to the nanobubbles generated on the surfaces of the porous structures of the AC. However, the current known methods are unable to measure the total loading amount of oxygen nanobubbles in particle suspensions, which can be essential for practical applications and manipulation of nanobubbles.

2.2. Quantification of Oxygen Nanobubble Loading in the Solid Suspension. In this study, an experimental apparatus was designed to measure the total amount of oxygen nanobubbles in the solid suspensions. Therefore, the total oxygen in the AC system was measured, which revealed that AC could be loaded with $2.85 \mathrm{mg} \mathrm{O}_{2} / \mathrm{g} \mathrm{AC}$ by the temperature gradient method. The principles of the current method are as follows: (1) by increasing the temperature and using mechanical stirring, the release of oxygen from the porous materials could be accelerated; (2) $\mathrm{N}_{2}$ gas was used as the
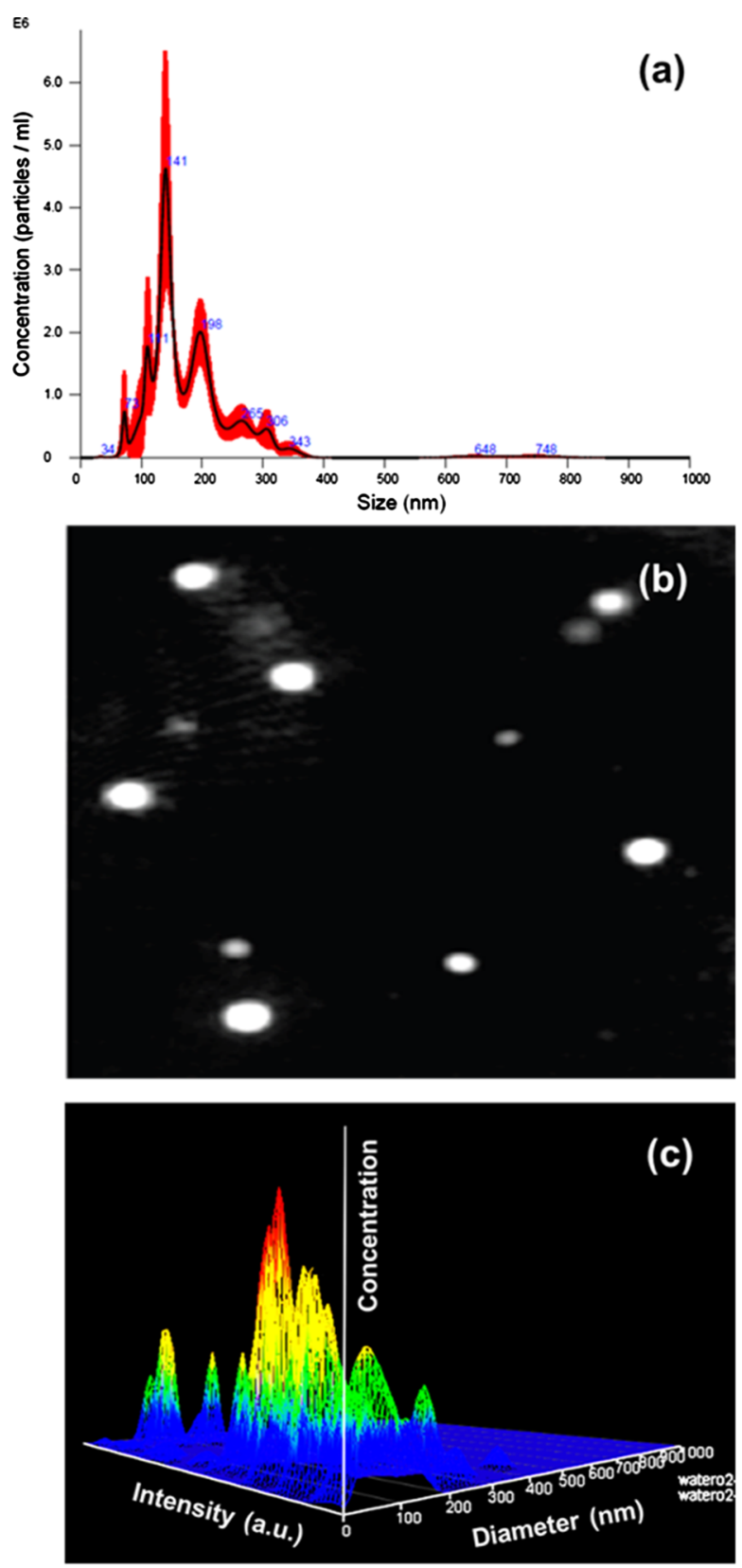

Figure 1. Determination of bulk nanobubbles in the water system; (a) determination of the particle size/concentration, (b) sample video frame, and (c) 3D graph (diameter vs intensity vs concentration).

circulation gas between two connected sealed flasks and this could also help to transfer oxygen released from the solid suspension in flask $A$ to absorption flask $\mathrm{B}$ with $\mathrm{Na}_{2} \mathrm{SO}_{3}$ as the oxygen reductant. Online dissolved oxygen (DO) measurements were used to determine the oxygen level in the two flasks, and the reaction was allowed to continue until the oxygen concentration reached zero in both flasks. It can be assumed that the oxygen was totally consumed by $\mathrm{Na}_{2} \mathrm{SO}_{3}$. Thus, the total oxygen in the suspensions can be obtained by calculating the amount of $\mathrm{Na}_{2} \mathrm{SO}_{3}$ consumed in the whole reaction process.

To improve the amount of oxygen loading in the porous materials, the high-pressure method was used in this work. Different materials were tested in this work, including AC, zeolite, biochar, diatomite, coal ash, and clay. From the results 

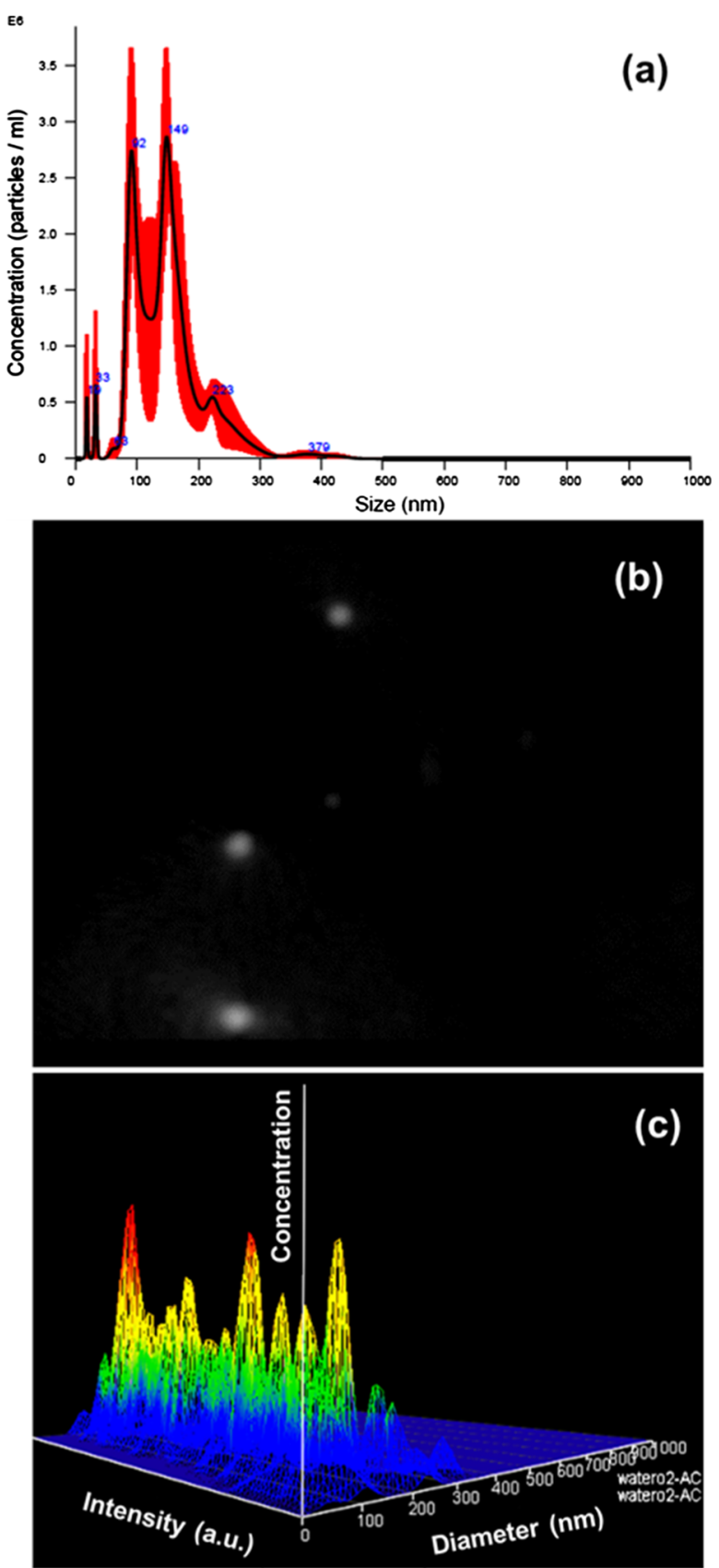

Figure 2. Nanobubbles generated by temperature variation in the system with AC; (a) determination of the particle size/concentration, (b) sample video frame, and (c) 3D graph (diameter vs intensity vs concentration).

in Figure 3, an oxygen loading of $31.75 \mathrm{mg} \mathrm{O}_{2} / \mathrm{g}$ was achieved for AC, which was higher than that obtained with other materials. Also, the high-pressure method dramatically improved the oxygen loading as compared with the temperature variation method $(2.85 \mathrm{mg} / \mathrm{g})$. The oxygen-loading capacities of zeolite, biochar, diatomite, coal ash, and clay were found to be 21.17, 20.11, 13.23, 5.09, and $4.87 \mathrm{mg} / \mathrm{g}$, respectively. These differences were mainly attributed to differences in the specific surface area and surface wettability. As shown in Figure 3, the oxygen-loading capacity of a material is correlated to its specific surface area. The formation of surface nanobubbles was strongly dependent on the nature of the substrates. Hydrophobic substrates experience long-range

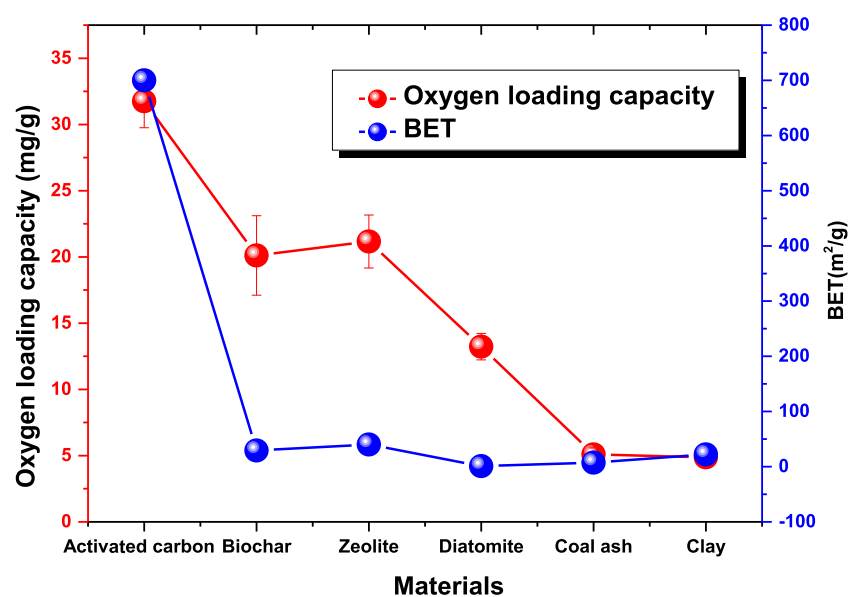

Figure 3. Oxygen-loading capacity vs specific surface area.

attraction between hydrophobic surfaces immersed in water, which is a much more suitable condition for nanobubble formation than is found with hydrophilic substrates. ${ }^{51,52} \mathrm{AC}$ is a hydrophobic porous material with a large specific surface area [Brunauer-Emmett-Teller (BET), $700 \mathrm{~m}^{2} / \mathrm{g}$ ], which presents the perfect conditions for nanobubble loading.

2.3. Potential Applications of Oxygen Nanobubble Loading Materials. The oxygen-releasing abilities of these samples were determined by testing the survival time of zebra fish in the deoxygenated ultrapure water system with 7 wt \% oxygen-modified materials. The control system contained only deoxygenated water. The zebra fish died after $1 \mathrm{~h}$ in the control system, while the survival times of the fish increased with the addition of oxygen-modified materials. As shown in Figure 4, zebra fish were still alive in the zeolite and AC systems after 20 $h$, which agrees with the experimental results showing that zeolite and AC have higher oxygen-loading capacities. Experiments were also carried out in the presence of materials without loading oxygen. The zebra fish has longer survival times than that in the control system, while its effect is much less than oxygen-modified materials, and all the zebra fish died in $3 \mathrm{~h}$ (Figure S1).

Materials containing oxygen nanobubbles may have potential applications in environmental remediation under anaerobic/anoxic conditions. In order to evaluate the anaerobic/anoxic remediation potential, another group of experiments were carried out in columns containing an anaerobic lake sediment and water. Oxygen-modified materials were added to the system, and a $1 \mathrm{~cm}$ capping layer was placed on the sediment-water interface. The system without any capping layer was set as the control column. As shown in Figure $5 \mathrm{a}$, the DO in the column was significantly increased with the addition of the oxygen-modified materials. Hence, the DO could last longer in all the treated systems than in the control system after 120 days of experiments. The oxidation reduction potential (ORP) of the sediment was significantly improved in the system with oxygen-modified materials and a capping layer (Figure 5b). This improvement will be helpful for remediation in anaerobic sediment environments, which can have long-term effects on microorganisms and the transformation of pollutants. ${ }^{53-57}$

In this work, the effect of oxygen-modified materials on the anaerobic remediation of a hydrophyte was also tested. Vallisneria spiralis seeds were used as the test model hydrophyte. In systems with oxygen-loaded zeolite, AC, and 


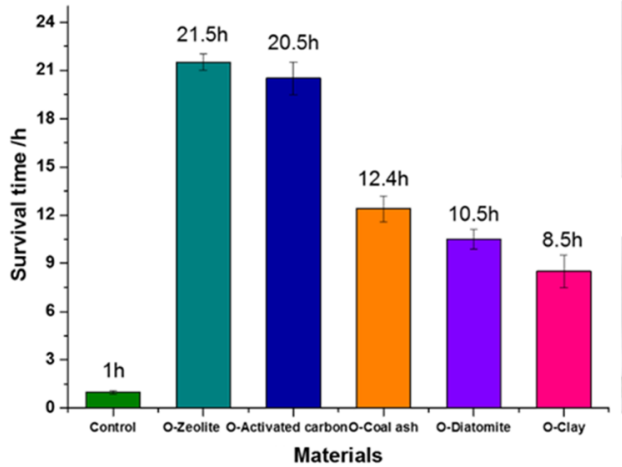

(a)

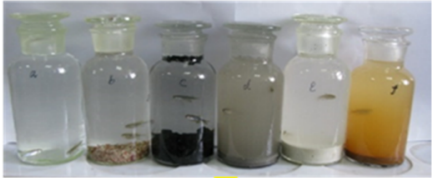

After $20 \mathrm{~h}$

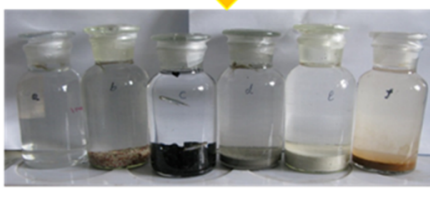

(b)

Figure 4. Effects of oxygen-modified materials on the survival time of zebra fish in the deoxygenated water. (a,b) Figures of the test.
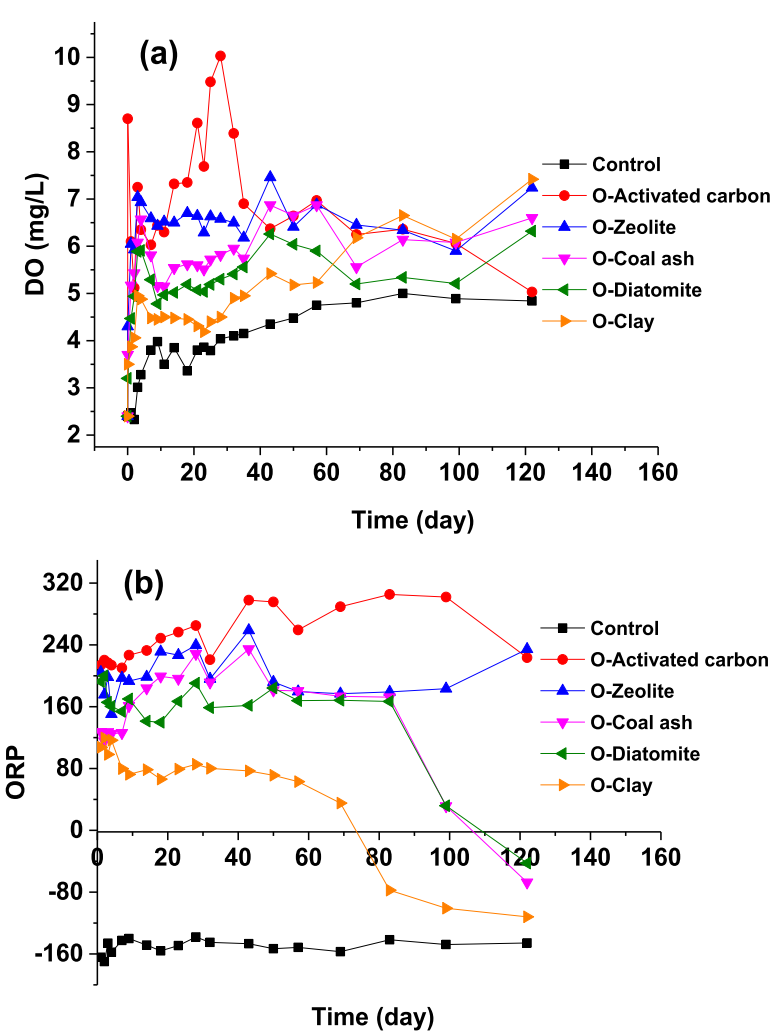

Figure 5. Effects of various oxygen-modified capping layers on the (a) DO and (b) ORP.

coal ash, the seed germination rates of Vallisneria spiralis were 73,67 , and 67\%, respectively (Figure 6), whereas the seed germination rate was only $27 \%$ in the control column. This implies that the presence of oxygen-modified diatomite and clay also improved the germination rates compared with the control system. However, the performance of these materials in terms of improving the germination rate was less than the other three materials because of their lower oxygen-loading capacity. This work has confirmed that nanobubbles could establish an important oxidative window for hydrophyte germination in an anaerobic sediment. ${ }^{58}$ These results corroborate previous findings where nanobubbles were effectively used to accelerate the metabolism of living organisms and seed germination by introducing reactive oxygen species. ${ }^{59-61}$ Current findings are also in accordance with reported studies wherein Brassica campestris and cucumber plants showed a significant increase in leaf weight and surface area in the presence of air-nanobubble solutions with higher DO concentrations compared to that of normal water. $^{5,62}$

\section{CONCLUSIONS}

We have presented a simple and cost-effective method for determining the total oxygen nanobubble loading in porous materials, which can be an important supplement to the existing methods of characterizing oxygen nanobubbles. The total oxygen loadings on AC, zeolite, biochar, diatomite, coal ash, and clay were found to be $31.75,21.17,20.11,13.23,5.09$, and $4.87 \mathrm{mg} / \mathrm{g}$, respectively. This difference is ascribed to their different properties, particularly the specific surface area and the hydrophobic or hydrophilic nature of the surface. These results will be useful for choosing among different possible materials for practical applications. Applications of these materials were assessed in anaerobic/anoxic conditions. The oxygen-loaded materials can prolong the survival time of zebra fish in a deoxygenated water system and improve the germination rate of Vallisneria spiralis in an anaerobic sediment. Our results have also demonstrated that a $1 \mathrm{~cm}$ capping layer containing oxygen nanobubbles could significantly improve the DO and ORP in an anaerobic aqueous system. Porous materials loaded with oxygen nanobubbles may have broad applications in environmental remediation. Although our results have provided a powerful characterization tool for oxygen nanobubbles in particulate matter, further research is needed to optimize the various effective parameters.

\section{METHODS}

4.1. Materials. AC (particle size: $4-6 \mathrm{~mm}$ ) and biochar were obtained from Henan province, China. Zeolite (particle size: $2-4 \mathrm{~mm}$ ) was obtained from Hebei province. Coal ash (Shanxi province, China) and clay (Beijing local soil) were washed with deionized water, dried at $100{ }^{\circ} \mathrm{C}$ for $24 \mathrm{~h}$, and then sieved through 180 mesh before use (particle size $<90$ $\mu \mathrm{m}) . \mathrm{Na}_{2} \mathrm{SO}_{3}$ and diatomite were purchased from Beijing Chemical Works (Beijing, China). Pure oxygen (99.99\%) was used in this experiment. All chemicals were analytical grade and used without further purification. Water was obtained from a Milli-Q system (Millipore Corp., Boston, MA).

4.2. Setup of Oxygen Measurement. The oxygen measurement setup was used as described in Figure 7 and consisted of two connected sealed flasks. Flask A contained experimental samples, such as solid suspensions, and flask B contained the oxygen absorption system. Flask A was kept in a water bath, which was used to manipulate the system 


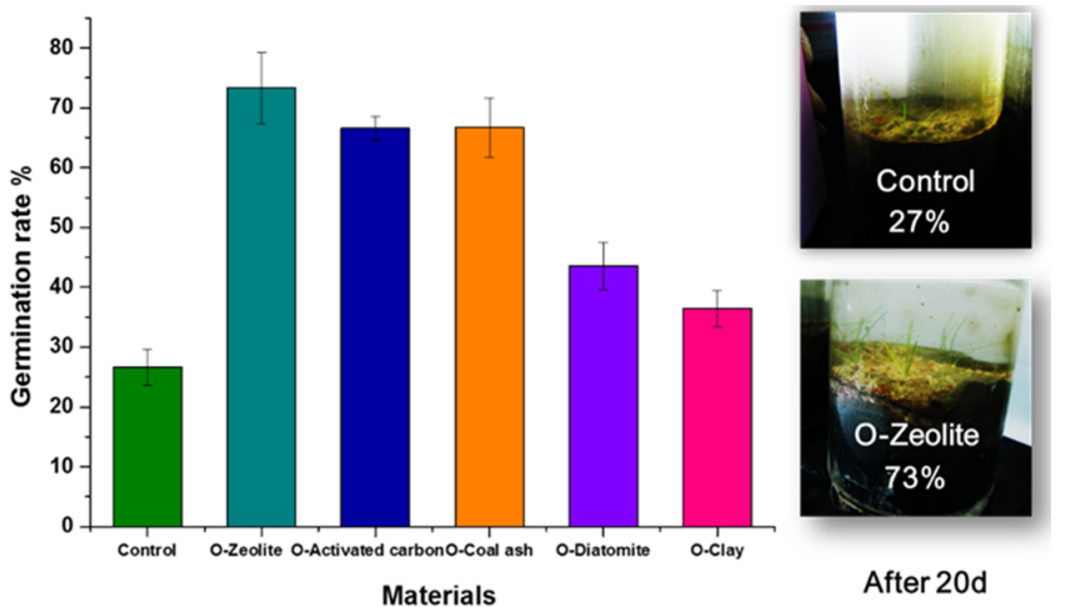

Figure 6. Effects of the oxygen-modified capping layer on the germination rate of Vallisneria spiralis. Oxygen-loaded materials include O-zeolite, O$\mathrm{AC}, \mathrm{O}$-coal ash, O-diatomite, and O-clay.

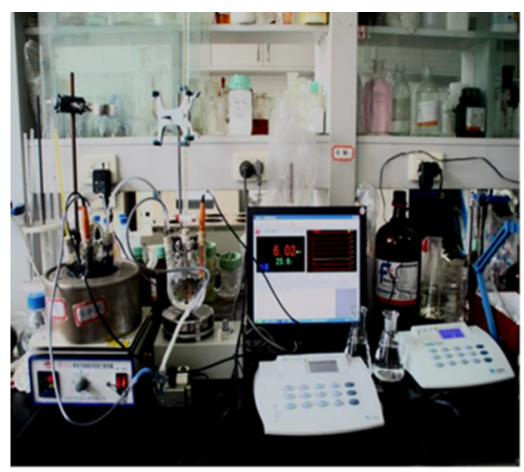

(a)

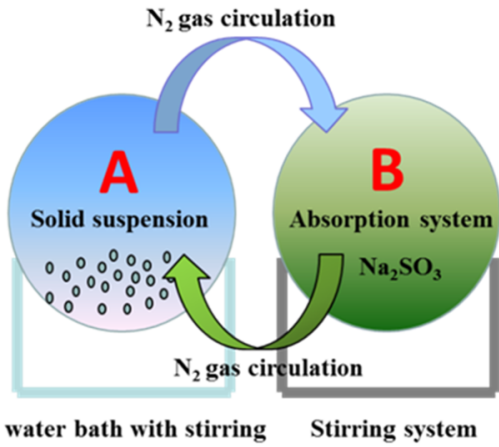

(b)

Figure 7. (a) Experimental setup and (b) schematic diagram of the equipment.

temperature, and both flasks were continuously stirred during the experiments. $\mathrm{N}_{2}$ gas was used as the circulation gas between flasks A and B. Oxygen released from the solid materials could be transferred into flask B. The total amount of oxygen in the suspensions could be obtained by measuring the amount of $\mathrm{Na}_{2} \mathrm{SO}_{3}$, which was used as the oxygen reductant in the reaction process. The DO meter was connected to a computer to record and measure the DO concentration in the reaction system in real time.

4.3. Sample Preparation and Characterization. In this work, nanobubbles were prepared by the temperature gradient method and the high-pressure loading method.

4.3.1. Temperature Gradient Method. An oxygen-saturated solution was obtained by purging pure oxygen into the solution. DO was measured by the DO meter (JPSJ605, Shanghai REX Instrument Factory). To prepare a sample, $2.5 \mathrm{~g}$ of AC was added to $500 \mathrm{~mL}$ of the solution, while ultrapure water was used as a control sample. All samples were placed in an ice bath, and the temperature was gradually increased from 5 to $60{ }^{\circ} \mathrm{C}$. The amount of free bulk nanobubbles was determined using NanoSight NTA technology (NS500, Bruker, Germany), and samples were filtrated by a $0.45 \mu \mathrm{m}$ membrane before measurement. The total amount of oxygen nanobubbles on the particle surface was determined by the absorbing method (Figure 7).

4.3.2. High-Pressure Method. The AC and zeolite particles were washed by water to remove any dust, and all the solid materials were dried at $100{ }^{\circ} \mathrm{C}$ for $24 \mathrm{~h}$ to remove water from the pores. The BET specific surface areas of the particles were determined using a surface area and porosity analyzer (ASAP 2020 HD88, Micromeritics). The obtained solid materials were kept in a container at $-0.075 \mathrm{MPa}$ for $2 \mathrm{~h}$ to remove air from the materials, and then the reactor was filled with pure $\mathrm{O}_{2}$, and a pressure of up to $0.15 \mathrm{MPa}$ was maintained for $0.5 \mathrm{~h}$. This step was repeated two times, and the pressure was then kept at $0.15 \mathrm{MPa}$ pressure for $12 \mathrm{~h}$ before the $\mathrm{O}_{2}$ pressure was slowly reduced to atmospheric pressure. Subsequently, the materials were removed, delivered into flask $\mathrm{A}$, and the online measurements were recorded.

4.4. Application of the Materials Containing Oxygen Nanobubbles. The column tests were conducted in the laboratory over a total duration of 120 days. The diameter and height of the column were 10 and $50 \mathrm{~cm}$, respectively. The anaerobic sediments were obtained from a lake (Taihu, China), and the height of the sediment was $5 \mathrm{~cm}$ at the bottom of the column. Water was added into the system. After 2 days of stabilization, the prepared materials containing oxygen nanobubbles were used to cap the sediment, and the height of the capping layer was $1 \mathrm{~cm}$. The DO in the system and the ORP of the sediment were determined by the MIparameter Meter (Hach, USA). Meanwhile Vallisneria spiralis seeds were sowed in each column. The germination rate of the seeds in the anaerobic sediment was also tested. A column without a capping layer was used as the control. The effects of 
the oxygen-modified materials on the survival time of zebra fish were observed in a deoxygenated water system with $7 \mathrm{wt} \%$ of modified materials. A timer was used to record the survival time of each fish in each system, and all experiments were repeated three times to obtain the mean survival time of the fish.

\section{ASSOCIATED CONTENT}

\section{S Supporting Information}

The Supporting Information is available free of charge on the ACS Publications website at DOI: 10.1021/acsomega.8b00784.

Effect of materials on the survival time of zebra fish in the deoxygenated water (PDF)

\section{AUTHOR INFORMATION}

\section{Corresponding Author}

*E-mail: gpan@rcees.ac.cn, gang.pan@ntu.ac.uk (G.P.).

\section{ORCID}

Gang Pan: 0000-0003-0920-3018

\section{Author Contributions}

L.W. and X.M. author with the same contribution to this work. All authors contributed to the experimental design and data analyses. The manuscript was written through contributions of all authors. All authors have given approval to the final version of the manuscript.

\section{Notes}

The authors declare no competing financial interest.

\section{ACKNOWLEDGMENTS}

This work was supported by the National Key R\&D Program of China (2017YFA0207203), the Key Research and Development Program of Ningxia (2017BY064), National Natural Science Foundation of China (21407160, 21107055), and Strategic Priority Research Program of the Chinese Academy of Sciences (XDA09030203).

\section{REFERENCES}

(1) Parker, J. L.; Claesson, P. M.; Attard, P. Bubbles, cavities, and the long-ranged attraction between hydrophobic surfaces. J. Phys. Chem. 1994, 98, 8468-8480.

(2) Ishida, N.; Inoue, T.; Miyahara, M.; Higashitani, K. Nano bubbles on a hydrophobic surface in water observed by tapping-mode atomic force microscopy. Langmuir 2000, 16, 6377-6380.

(3) Lou, S.-T.; Ouyang, Z.-Q.; Zhang, Y.; Li, X.-J.; Hu, J.; Li, M.-Q.; Yang, F.-J. Nanobubbles on solid surface imaged by atomic force microscopy. J. Vac. Sci. Technol., B: Microelectron. Nanometer Struct.Process., Meas., Phenom. 2000, 18, 2573.

(4) Cai, W. B.; Yang, H. L.; Zhang, J.; Yin, J. K.; Yang, Y. L.; Yuan, L. J.; Zhang, L.; Duan, Y. Y. The optimized fabrication of nanobubbles as ultrasound contrast agents for tumor imaging. Sci. Rep. 2015, 5, 13725 .

(5) Ebina, K.; Shi, K.; Hirao, M.; Hashimoto, J.; Kawato, Y.; Kaneshiro, S.; Morimoto, T.; Koizumi, K.; Yoshikawa, H. Oxygen and air nanobubble water solution promote the growth of plants, fishes, and mice. PLoS One 2013, 8, e65339.

(6) Agarwal, A.; Ng, W. J.; Liu, Y. Principle and applications of microbubble and nanobubble technology for water treatment. Chemosphere 2011, 84, 1175-1180.

(7) Lou, S. T.; Gao, J. X.; Xiao, X. D.; Li, X. J.; Li, G. L.; Zhang, Y.; Li, M. Q.; Sun, J. L.; Hu, J. Nanobubbles at the liquid/solid interface studied by atomic force microscopy. Chin. Phys. 2001, 10, S108S110.
(8) Guo, W.; Shan, H.; Guan, M.; Gao, L.; Liu, M.; Dong, Y. Investigation on nanobubbles on graphite substrate produced by the water- $\mathrm{NaCl}$ solution replacement. Surf. Sci. 2012, 606, 1462-1466.

(9) An, H.; Tan, B. H.; Zeng, Q.; Ohl, C.-D. Stability of nanobubbles formed at the interface between cold water and hot highly oriented pyrolytic graphite. Langmuir 2016, 32, 11212-11220.

(10) Wang, L.; Miao, X.; Pan, G. Microwave-induced interfacial nanobubbles. Langmuir 2016, 32, 11147-11154.

(11) Zhang, L.; Zhang, Y.; Zhang, X.; Li, Z.; Shen, G.; Ye, M.; Fan, C.; Fang, H.; Hu, J. Electrochemically controlled formation and growth of hydrogen nanobubbles. Langmuir 2006, 22, 8109-8113.

(12) Chen, Q.; Luo, L.; White, H. S. Electrochemical generation of a hydrogen bubble at a recessed platinum nanopore electrode. Langmuir 2015, 31, 4573-4581.

(13) Chen, Q.; Wiedenroth, H. S.; German, S. R.; White, H. S. Electrochemical nucleation of stable $\mathrm{N}_{2}$ nanobubbles at Pt nanoelectrodes. J. Am. Chem. Soc. 2015, 137, 12064-12069.

(14) Yang, S.; Tsai, P.; Kooij, E. S.; Prosperetti, A.; Zandvliet, H. J. W.; Lohse, D. Electrolytically generated nanobubbles on highly orientated pyrolytic graphite surfaces. Langmuir 2009, 25, 14661474.

(15) Borkent, B. M.; Dammer, S. M.; Schönherr, H.; Vancso, G. J.; Lohse, D. Superstability of surface nanobubbles. Phys. Rev. Lett. 2007, 98, 204502.

(16) Craig, V. S. J. Very small bubbles at surfaces-the nanobubble puzzle. Soft Matter 2011, 7, 40-48.

(17) Tyrrell, J. W. G.; Attard, P. Atomic force microscope images of nanobubbles on a hydrophobic surface and corresponding forceseparation data. Langmuir 2002, 18, 160-167.

(18) Zhang, X. H.; Maeda, N.; Hu, J. Thermodynamic stability of interfacial gaseous states. J. Phys. Chem. B 2008, 112, 13671-13675.

(19) Seddon, J. R. T.; Bliznyuk, O.; Kooij, E. S.; Poelsema, B.; Zandvliet, H. J. W.; Lohse, D. Dynamic dewetting through micropancake growth. Langmuir 2010, 26, 9640-9644.

(20) An, H.; Liu, G.; Craig, V. S. J. Wetting of nanophases: nanobubbles, nanodroplets and micropancakes on hydrophobic surfaces. Adv. Colloid Interface Sci. 2015, 222, 9-17.

(21) Ohgaki, K.; Khanh, N. Q.; Joden, Y.; Tsuji, A.; Nakagawa, T. Physicochemical approach to nanobubble solutions. Chem. Eng. Sci. 2010, 65, 1296-1300.

(22) Zhu, J.; An, H.; Alheshibri, M.; Liu, L.; Terpstra, P. M. J.; Liu, G.; Craig, V. S. J. Cleaning with bulk nanobubbles. Langmuir 2016, 32, 11203-11211.

(23) Zhang, X. H.; Li, G.; Maeda, N.; Hu, J. Removal of induced nanobubbles from water/graphite interfaces by partial degassing. Langmuir 2006, 22, 9238-9243.

(24) An, H.; Liu, G.; Atkin, R.; Craig, V. S. J. Surface nanobubbles in nonaqueous media: looking for nanobubbles in dmso, formamide, propylene carbonate, ethylammonium nitrate, and propylammonium nitrate. ACS Nano 2015, 9, 7596-7607.

(25) An, H.; Tan, B. H.; Ohl, C.-D. Distinguishing nanobubbles from nanodroplets with AFM: the influence of vertical and lateral imaging forces. Langmuir 2016, 32, 12710-12715.

(26) Zhang, X. H.; Zhang, X. D.; Lou, S. T.; Zhang, Z. X.; Sun, J. L.; $\mathrm{Hu}, \mathrm{J}$. Degassing and temperature effects on the formation of nanobubbles at the mica/water interface. Langmuir 2004, 20, 38133815.

(27) Holmberg, M.; Kühle, A.; Mørch, K. A.; Boisen, A.; Boisen, A. Nanobubble trouble on gold surfaces. Langmuir 2003, 19, 1051010513.

(28) Simonsen, A. C.; Hansen, P. L.; Klösgen, B. Nanobubbles give evidence of incomplete wetting at a hydrophobic interface. J. Colloid Interface Sci. 2004, 273, 291-299.

(29) Agrawal, A.; Park, J.; Ryu, D. Y.; Hammond, P. T.; Russell, T. P.; McKinley, G. H. Controlling the location and spatial extent of nanobubbles using hydrophobically nanopatterned surfaces. Nano Lett. 2005, 5, 1751-1756. 
(30) Switkes, M.; Ruberti, J. W. Rapid cryofixation/freeze fracture for the study of nanobubbles at solid-liquid interfaces. Appl. Phys. Lett. 2004, 84, 4759-4761.

(31) Pan, G.; He, G.; Zhang, M.; Zhou, Q.; Tyliszczak, T.; Tai, R.; Guo, J.; Bi, L.; Wang, L.; Zhang, H. Nanobubbles at hydrophilic particle-water interfaces. Langmuir 2016, 32, 11133-11137.

(32) Zhang, X. H.; Zhang, X.; Sun, J.; Zhang, Z.; Li, G.; Fang, H.; Xiao, X.; Zeng, X.; Hu, J. Detection of novel gaseous states at the highly oriented pyrolytic graphite-water interface. Langmuir 2007, 23, 1778-1783.

(33) Hampton, M. A.; Nguyen, A. V. Nanobubbles and the nanobubble bridging capillary force. Adv. Colloid Interface Sci. 2010, $154,30-55$

(34) Wang, Y.; Bhushan, B. Boundary slip and nanobubble study in micro/nanofluidics using atomic force microscopy. Soft Matter 2010, 6, 29-66.

(35) Rettew, R. E.; Allam, N. K.; Alamgir, F. M. Interface architecture determined electrocatalytic activity of $\mathrm{Pt}$ on vertically oriented $\mathrm{TiO}_{2}$ nanotubes. ACS Appl. Mater. Interfaces 2011, 3, 147151.

(36) Ibrahimkutty, S.; Kim, J.; Cammarata, M.; Ewald, F.; Choi, J.; Ihee, H.; Plech, A. Ultrafast structural dynamics of the photocleavage of protein hybrid nanoparticles. ACS Nano 2011, 5, 3788-3794.

(37) Chakraborty, S. Order parameter modeling of fluid dynamics in narrow confinements subjected to hydrophobic interactions. Phys. Rev. Lett. 2007, 99, 094504.

(38) Janib, S. M.; Moses, A. S.; MacKay, J. A. Imaging and drug delivery using theranostic nanoparticles. Adv. Drug Delivery Rev. 2010 62, 1052-1063.

(39) Ferrara, K. W.; Borden, M. A.; Zhang, H. Lipid-shelled vehicles: engineering for ultrasound molecular imaging and drug delivery. Acc. Chem. Res. 2009, 42, 881-892.

(40) Wang, X.; Zhang, Y. Degradation of alachlor in aqueous solution by using hydrodynamic cavitation. J. Hazard. Mater. 2009, 161, 202-207.

(41) Tasaki, T.; Wada, T.; Baba, Y.; Kukizaki, M. Degradation of surfactants by an integrated nanobubbles/VUV irradiation technique. Ind. Eng. Chem. Res. 2009, 48, 4237-4244.

(42) Tasaki, T.; Wada, T.; Fujimoto, K.; Kai, S.; Ohe, K.; Oshima, T.; Baba, Y.; Kukizaki, M. Degradation of methyl orange using shortwavelength UV irradiation with oxygen microbubbles. J. Hazard. Mater. 2009, 162, 1103-1110.

(43) Zhang, H.; Lyu, T.; Bi, L.; Tempero, G.; Hamilton, D. P.; Pan, G. Combating hypoxia/anoxia at sediment-water interfaces: a preliminary study of oxygen nanobubble modified clay materials. Sci. Total Environ. 2018, 637-638, 550-560.

(44) Shi, W.; Pan, G.; Chen, Q.; Song, L.; Zhu, L.; Ji, X. Hypoxia remediation and methane emission manipulation using surface oxygen nanobubbles. Environ. Sci. Technol. 2018, 52, 8712.

(45) Pan, G.; Chen, J.; Anderson, D. M. Modified local sands for the mitigation of harmful algal blooms. Harmful Algae 2011, 10, 381387.

(46) Pan, G.; Yang, B.; Wang, D.; Chen, H.; Tian, B.-h.; Zhang, M.1.; Yuan, X.-z.; Chen, J. In-lake algal bloom removal and submerged vegetation restoration using modified local soils. Ecol. Eng. 2011, 37, $302-308$.

(47) Pan, G.; Dai, L.; Li, L.; He, L.; Li, H.; Bi, L.; Gulati, R. D. Reducing the recruitment of sedimented algae and nutrient release into the overlying water using modified soil/sand flocculation-capping in eutrophic lakes. Environ. Sci. Technol. 2012, 46, 5077-5084.

(48) Spears, B. M.; Maberly, S. C.; Pan, G.; Mackay, E.; Bruere, A.; Corker, N.; Douglas, G.; Egemose, S.; Hamilton, D.; Hatton-Ellis, T.; Huser, B.; Li, W.; Meis, S.; Moss, B.; Lürling, M.; Phillips, G.; Yasseri, S.; Reitzel, K. Geo-engineering in lakes: a crisis of confidence? Environ. Sci. Technol. 2014, 48, 9977-9979.

(49) Seddon, J. R. T.; Kooij, E. S.; Poelsema, B.; Zandvliet, H. J. W.; Lohse, D. Surface bubble nucleation stability. Phys. Rev. Lett. 2011, 106, 056101.
(50) Yang, S.; Dammer, S. M.; Bremond, N.; Zandvliet, H. J. W.; Kooij, E. S.; Lohse, D. Characterization of nanobubbles on hydrophobic surfaces in water. Langmuir 2007, 23, 7072-7077.

(51) Steitz, R.; Gutberlet, T.; Hauss, T.; Klösgen, B.; Krastev, R.; Schemmel, S.; Simonsen, A. C.; Findenegg, G. H. Nanobubbles and their precursor layer at the interface of water against a hydrophobic substrate. Langmuir 2003, 19, 2409-2418.

(52) Zhang, L.; Zhang, X.; Fan, C.; Zhang, Y.; Hu, J. Nanoscale multiple gaseous layers on a hydrophobic surface. Langmuir 2009, 25, $8860-8864$

(53) Rassamee, V.; Sattayatewa, C.; Pagilla, K.; Chandran, K. Effect of oxic and anoxic conditions on nitrous oxide emissions from nitrification and denitrification processes. Biotechnol. Bioeng. 2011, 108, 2036-2045.

(54) De Vittor, C.; Relitti, F.; Kralj, M.; Covelli, S.; Emili, A. Oxygen, carbon, and nutrient exchanges at the sediment-water interface in the Mar Piccolo of Taranto (Ionian Sea, southern Italy). Environ. Sci. Pollut. Res. 2016, 23, 12566-12581.

(55) Zhu, G.; Wang, S.; Wang, W.; Wang, Y.; Zhou, L.; Jiang, B.; Op den Camp, H. J. M.; Risgaard-Petersen, N.; Schwark, L.; Peng, Y.; Hefting, M. M.; Jetten, M. S. M.; Yin, C. Hotspots of anaerobic ammonium oxidation at land-freshwater interfaces. Nat. Geosci. 2013, $6,103-107$.

(56) Brzozowska, R.; Gawrońska, H. The influence of a long-term artificial aeration on the nitrogen compounds exchange between bottom sediments and water in Lake Dlugie. Oceanol. Hydrobiol. Stud. 2009, 38, 113-119.

(57) Funes, A.; de Vicente, J.; Cruz-Pizarro, L.; Álvarez-Manzaneda, I.; de Vicente, I. Magnetic microparticles as a new tool for lake restoration: a microcosm experiment for evaluating the impact on phosphorus fluxes and sedimentary phosphorus pools. Water Res. 2016, 89, 366-374.

(58) Bailly, C.; El-Maarouf-Bouteau, H.; Corbineau, F. From intracellular signaling networks to cell death: the dual role of reactive oxygen species in seed physiology. Comptes Rendus Biol. 2008, 331, $806-814$.

(59) Liu, S.; Oshita, S.; Kawabata, S.; Makino, Y.; Yoshimoto, T. Identification of ROS produced by nanobubbles and their positive and negative effects on vegetable seed germination. Langmuir 2016, $32,11295-11302$.

(60) Liu, S.; Oshita, S.; Makino, Y.; Wang, Q.; Kawagoe, Y.; Uchida, T. Oxidative capacity of nanobubbles and its effect on seed germination. ACS Sustain. Chem. Eng. 2016, 4, 1347-1353.

(61) Owusu-Ansah, E.; Banerjee, U. Reactive oxygen species prime drosophila haematopoietic progenitors for differentiation. Nature 2009, 461, 537-541.

(62) Yoshida, S.; Kitano, M.; Eguchi, H. Water uptake and growth of cucumber plants (Cucumis sativus L.) under control of dissolved $\mathrm{O}_{2}$ concentration in hydroponics. Acta Hortic. 1996, 440, 199-204. 